\title{
Maternal lifestyle factors in pregnancy and congenital heart defects in offspring: review of the current evidence
}

\author{
Yu Feng ${ }^{1 \dagger}$, Di Yu ${ }^{1 \dagger}$, Lei Yang ${ }^{1}$, Min Da ${ }^{1}$, Zhiqi Wang ${ }^{1}$, Yuan $\mathrm{Lin}^{2}$, Bixian $\mathrm{Ni}^{2}$, Song Wang ${ }^{1}$ and Xuming $\mathrm{Mo}^{1 *}$
}

\begin{abstract}
The prognosis of children with congenital heart defects(CHDs) continues to improve with advancing surgical techniques; however, lack of information about modifiable risk factors for malformations in cardiovascular development impeded the prevention of $\mathrm{CHDs}$. We investigated an association between maternal lifestyle factors and the risk of $\mathrm{CHDs}$, because epidemiological studies have reported conflicting results regarding maternal lifestyle factors and the risk of CHDs recently. A review published on 2007 provided a summary of maternal exposures associated with an increased risk of CHDs. As part of noninherited risk factors, we conducted a brief overview of studies on the evidence linking common maternal lifestyle factors, specifically smoking, alcohol, illicit drugs, caffeine, body mass index and psychological factors to the development of CHDs in offspring. Women who smoke and have an excessive body mass index(BMI) during pregnancy are suspected to be associated with CHDs in offspring. Our findings could cause public health policy makers to pay more attention to women at risk and could be used in the development of population-based prevention strategies to reduce the incidence and burden of $\mathrm{CHDs}$. However, more prospective studies are needed to investigate the association between maternal lifestyle factors and CHDs.
\end{abstract}

Keywords: Congenital heart defects, Maternal lifestyle factors, Smoking, BMl

\section{Introduction}

Congenital heart defects (CHD) are the most common human birth defects and the leading cause of perinatal mortality, with an incidence of approximately 4 to 50 per 1000 live birth or even higher [1,2]. With the advancing surgical techniques, prognosis of children with complicated and uncomplicated CHDs continues to improve, but the reported incidence remains unchanged [3]. Clinicians and basic scientists have long understood the sources of these cardiovascular developmental errors, and there is wide acceptance of the opinion that that the etiology of CHD is complex and possibly lies within the interaction of environmental exposures and inherited factors [4]. However, lack of enough information about modifiable risk factors for malformations in fetal heart development has impeded the prevention of CHDs.

\footnotetext{
* Correspondence: mohsuming15@sina.com

${ }^{\dagger}$ Equal contributors

'Department of Cardiothoracic Surgery, The Affiliated Children's Hospital of Nanjing Medical University, Nanjing, Jiangsu, P.R. China

Full list of author information is available at the end of the article
}

Although CHDs can occur in the setting of multiple birth defects as part of a syndrome, most are found as isolated defects with no syndromic association. Over the past decade, a multitude of research studies have identified both chromosomal and gene mutations as causation for the syndromic heart malformation [5,6]. While the origin of non-syndromic CHD that accounts for most of all congenital cardiac abnormalities is still under the veil waiting to be further uncovered. Relatively less information has been reported on noninherited factors that may have an adverse effect on the cardiovascular development, which has made it difficult to create population-based strategies to reduce the burden of illness from CHDs and for couples to choose lifestyles to reduce the risk of delivering a child with CHDs.

Recent epidemiologic studies have demonstrated an association between maternal lifestyle factors, specifically smoking, alcohol, illicit drugs use, caffeine use, body mass index and psychological factors and the risk of CHDs in offspring. A review published on 2007 provided a summary of well-known prenatal maternal conditions or 
exposures associated with an increased risk for cardiac defects [7]. As part of noninherited risk factors, we conducted a brief overview of studies on the evidence linking common maternal lifestyle factors during pregnancy to the development of CHDs in offspring.

\section{Maternal lifestyle factors and CHD}

The studies that reported the association between maternal lifestyle factors during pregnancy and the risk of offspring with CHDs were summarized in Table 1.

\section{Evidence of maternal smoking during pregnancy and CHD}

A study by Alberman et al. [31] was one of the first to report the association between maternal cigarette smoking and CHDs. However, the evidence since then has been mixed, with some studies showing positive associations and others providing null results. To date, a total of three meta-analyses have investigated the association between maternal smoking during pregnancy and CHDs in offspring. The first meta-analysis published on1999 found no association for all CHDs combined (OR, 1.07; 95\% CI, $0.98-1.17)$ and mixed results for analyses of specific groups or phenotypes [8]. The second meta-analysis by Hackshaw et al. [9] estimated the effects of maternal smoking across a spectrum of birth defects including heart defects (OR, 1.09; 95\% CI, 1.02-1.17). However, the study did not evaluate the effects of maternal smoking on CHD subtypes, and dose-response relationships (i.e., increasing levels of smoking) were not assessed. A latest meta-analysis [10] of studies published between 1971 and 2011 (23 case-control studies, 5 cohort studies, and 5 cross-sectional studies) found positive association for all CHDs combined (RR, 1.11; 95\% CI, 1.02-1.21). According to analysis, as for specific groups, women who smoked during pregnancy were more likely to give birth to a child with 12 of 17 CHD subtypes analyzed compared with nonsmoker. The highest risk was for septal defects as a group (RR, 1.44; 95\% CI, 1.16-1.79). After that, a recent study reported that only valvar pulmonary stenosis(VPS) was highly associated with mothers who smoked 20 cigarettes or more per day $(P=0.03)$. When both mother and father consumed at least 20 cigarettes per day, VPS and coarctation of the aorta would have a significant p-value (0.03 and 0.02 respectively) [32]. Another study reported as opposed to smoking or high BMI alone, the risk for CHD in the offspring of women with high BMI $\left(\geq 25 \mathrm{~kg} / \mathrm{m}^{2}\right)$ who also smoked was significantly increased. The adjusted OR was 2.65 (95\% CI, 1.20-5.87) for all CHD, 2.60 (95\% CI, 1.05- 6.47) for septal defects and 3.58 (95\% CI, 1.46- 8.79) for outflow tract anomalies [11]. Recent analyses of small case groups based on the National Birth Defects Prevention Study(NBDPS) data have identified associations between maternal smoking and atrioventricular septal defects (AVSDs) [12].
The different results for analyses of specific groups of CHDs probably reflect methodological limitations, and other environmental factors. Further research based on large population using standardized ascertainment of case and classification methods is needed to determine whether there is an association between maternal smoking and the risk of CHDs in offspring.

\section{Evidence of maternal alcohol consumption during pregnancy and CHD}

Ever since the first description of the fetal alcohol syndrome by Jones and Smith in 1973 [33], many observational studies have been published on the topic of alcohol consumption in pregnant women and the effects on the development of their fetus and child, including cardiac defects. Recently, a total of seven studies investigate the association between maternal alcohol consumption during the pregnancy and CHDs. A population-based case-control study of California births indicated that compared with nonconsumers, women who consumed alcohol less than once a week had a 1.3-fold higher risk of having infants with a conotruncal heart defect $(95 \% \mathrm{CI}$, 1.00 - 1.90), and women who consumed alcohol once a week or more had a 1.9 -fold increase in risk $(95 \% \mathrm{CI}$, 1.00 - 3.40) [13]. In another population-based case-control study among a cohort of California births between July 1999 and June 2003, maternal consumption of alcohol less than one day per week was associated with a 2.1-fold increased risk of d-transposition of the great arteries (95\% CI, 1.10- 3.20) [14]. According to a cohort study including 80,346 pregnant women enrolled into the Danish National Birth Cohort, exposure to low-to-moderate levels of alcohol on a weekly basis or occasional binge drinking during pregnancy was not statistical significantly increased risk of isolated ventricular septal defect(VSD) and atrial septal defect(ASD) in offspring [15]. For binge drinking, a case-control study in the Pregnancy Risk Assessment Monitoring System (PRAMS) showed significantly increased risk of CHDs among mothers who reported binge drinking more than once compared to mothers who did not report binge drinking in the 3 months prior to pregnancy (OR, 2.99; 95\% CI, 1.197.51) [16]. Two more recent cohort studies in Canada and Australia reported a significant association between maternal alcohol consumption during pregnancy and overall CHDs (OR, 1.90; 95\% CI, 1.70- 2.00) or ASD (OR, 1.36; 95\% CI, 1.14- 1.63) and VSD (OR, 1.77; 95\% CI, 1.27 - 2.46), respectively $[17,18]$. However, other studies have failed to identify an association [19].

\section{Evidence of maternal illicit drug use during pregnancy and CHD}

Illicit drug use was recorded for marijuana, hashish, cocaine, hallucinogens, heroin, and methadone. Marijuana 
Table 1 Maternal lifestyle factors and the risk of offspring with congenital heart defects

\begin{tabular}{|c|c|c|c|c|c|c|}
\hline $\begin{array}{l}\text { Maternal } \\
\text { lifestyle factors }\end{array}$ & Study design & Study period & Outcome & Exposure & $\mathrm{OR}(95 \% \mathrm{Cl})$ & Reference \\
\hline \multirow[t]{8}{*}{ Cigarette smoking } & Meta-ananlysis & 1971-1999 & CHD combined & Smoking & 1.07(0.98-1.17) & {$[8]$} \\
\hline & Meta-ananlysis & 1959-2010 & CHD combined & Smoking & $1.09(1.02-1.17)$ & {$[9]$} \\
\hline & Meta-ananlysis & 1971-2011 & CHD combined & Smoking & $1.11(1.02-1.21)$ & {$[10]$} \\
\hline & & & VSD & Smoking & 1.44(1.16-1.79) & \\
\hline & Case-control & 1997-2008 & CHD combined & Smoking, $\mathrm{BMl} \geq 25 \mathrm{~kg} / \mathrm{m}^{2}$ & $2.65(1.20-5.87)$ & {$[11]$} \\
\hline & & & Septal defects & Smoking, BMl $\geq 25 \mathrm{~kg} / \mathrm{m}^{2}$ & $2.60(1.05-6.47)$ & \\
\hline & & & Outflow tract anomalies & Smoking, $\mathrm{BMl} \geq 25 \mathrm{~kg} / \mathrm{m}^{2}$ & $3.58(1.46-8.79)$ & \\
\hline & Case-control & 1997-2005 & AVSD & Smoking & $1.50(1.10-2.40)$ & {$[12]$} \\
\hline \multirow[t]{11}{*}{ Alcohol consumption } & Case-control & 1987-1988 & CTD & Drink less than once a week & 1.30(1.10-1.90) & [13] \\
\hline & & & & Drink once a week or more & $1.90(1.00-1.34)$ & \\
\hline & Case-control & 1999-2003 & TGA & Drink less than one day per week & $2.10(1.10-3.20)$ & {$[14]$} \\
\hline & Cohort & 1996-2002 & VSD & Low-to-moderate levels of alcohol & $1.10(0.54-2.23)$ & {$[15]$} \\
\hline & & & ASD & Low-to-moderate levels of alcohol & $0.66(0.27-1.62)$ & \\
\hline & Case-control & 1996-2005 & CHD combined & Binge drinking & $2.99(1.19-7.51)$ & {$[16]$} \\
\hline & Cohort & 1983-2007 & ASD & Alcohol Diagnosis & 1.36(1.14- 1.63) & {$[17]$} \\
\hline & & & VSD & Alcohol Diagnosis & $1.77(1.272 .46)$ & \\
\hline & Cohort & $2002-2010$ & CHD combined & Alcohol use & $1.90(1.70-2.00)$ & {$[18]$} \\
\hline & Case-control & 1999-2005 & CHD combined & Drink several times a week & $1.73(0.52-5.70)$ & {$[19]$} \\
\hline & & & & Drink several times a month & 1.34(0.79-2.24) & \\
\hline \multirow[t]{4}{*}{ Illicit drug use } & Case-control & 1968-1980 & VSD & Cannabis use & $2.35(1.43-3.86)$ & {$[20]$} \\
\hline & & & & $\begin{array}{l}\text { Cannabis use for three } \\
\text { or more days per week }\end{array}$ & $3.73(1.56-8.96)$ & \\
\hline & Case-control & 1981-1989 & VSD & Cocaine & $2.99(1.69-5.30)$ & {$[21]$} \\
\hline & Case-control & 1981-1989 & Single ventricle & Marijuana & $0.90(0.10-6.90)$ & {$[22]$} \\
\hline \multirow[t]{8}{*}{ Caffeine Use } & Systematic review & 1966-2004 & CHD combined & Coffee & $1.10(0.90-1.50)$ & {$[23]$} \\
\hline & & & & Tea & $1.00(0.90-1.20)$ & \\
\hline & Case-control & 1996-1998 & CHD in Down syndrome & Any caffeine & $0.89(0.42-1.88)$ & {$[24]$} \\
\hline & & & & Coffee & $0.75(0.39-1.44)$ & \\
\hline & & & & Tea & $1.11(0.60-2.03)$ & \\
\hline & & & & Cola & $0.69(0.38-1.27)$ & \\
\hline & & & & Cocoa & 3.95(0.81-19.2) & \\
\hline & Case-control & 1991-1993 & CHD in Down syndrome & $\geq 4$ cups of coffee vs. $<4$ cups & $1.50(0.70-3.30)$ & {$[25]$} \\
\hline \multirow[t]{9}{*}{ BMl } & Meta-ananlysis & 1996-2008 & CHD combined & Obesity & $1.30(1.12-1.51)$ & {$[26]$} \\
\hline & & & Septal anomalies & Obesity & $1.20(1.09-1.31)$ & \\
\hline & & & TOF & Obesity & 1.10(0.76-1.61) & \\
\hline & & & TGA & Obesity & $1.41(0.97-2.06)$ & \\
\hline & Meta-ananlysis & 1969-2012 & CHD combined & Overweight & $1.08(1.02-1.15)$ & {$[27]$} \\
\hline & & & & Moderate obesity & 1.15(1.11-1.20) & \\
\hline & & & & Severe obesity & $1.39(1.31-1.47)$ & \\
\hline & & & TOF & Severe obesity & $1.94(1.49-2.51)$ & \\
\hline & & & AVS & Underweight & $1.47(1.01-2.15)$ & \\
\hline
\end{tabular}


Table 1 Maternal lifestyle factors and the risk of offspring with congenital heart defects (Continued)

\begin{tabular}{|c|c|c|c|c|c|c|}
\hline & Case-control & 2004-2009 & PAS & Obesity & $1.36(1.17-1.58)$ & [28] \\
\hline & & & TOF & Obesity & $1.62(1.30-2.02)$ & \\
\hline & & & TGA & Obesity & $1.45(1.16-1.80)$ & \\
\hline & & & VSD & Obesity & $1.15(1.07-1.23)$ & \\
\hline \multirow[t]{3}{*}{ Psychological factors } & Case-control & 1978-2008 & CHD combined & Bereavement & $1.11(1.00-1.22)$ & [29] \\
\hline & Case-control & 2004-2005 & CHD combined & Mental stress & $3.93(1.94-7.94)$ & [30] \\
\hline & Case-control & 1996-2005 & CHD combined & High stress level vs. low stress level & $0.74(0.45-1.22)$ & [25] \\
\hline
\end{tabular}

Abbreviation: CHD, congenital heart defect; VSD, Ventricular Septal Defect; ASD, Atrial Septal Defect; TOF, Tetralogy of Fallot; TGA, Transposition of the Great Arteries; AVSD, Atrioventricular Septal Defect; CTD,Conotruncal defects; PVS, Pulmonary valve stenosis; COA, Coarctation of the aorta; AVS, Aortic valve stenosis; PAS, pulmonary artery stenosis.

and hashish use were combined to reflect cannabis exposure. A case-control study in Atlanta reported maternal cannabis use, according to self- and proxy-report, was associated with a two-fold increased risk of VSD. Selfreported cannabis use for fewer than three days per week resulted in a similar OR, while use three or more days per week resulted in an almost four-fold increased risk (OR, 3.73; 95\% CI, 1.56- 8.96) [20]. A case-control study using data from the Baltimore-Washington Infant Study (BWIS) examined the association between maternal cocaine use and isolated membranous ventricular septal defects (VSD). An OR of 2.99 for maternal cocaine use dropped to 2.15 when taking into account paternal cocaine use (a change of 28\%) and to 2.52 when paternal marijuana use was considered (a change of 16\%). Although maternal cocaine use was an effect modifier for paternal cocaine use, it was not statistically significant as an independent risk factor [21]. Another case-control study of single ventricle using data from the BWIS reported no association between maternal marijuana and single ventricle in infants (OR, 0.90; 95\% CI, 0.10-6.90) [22]. Further studies are warranted to elucidate the possible association of illicit drug use with CHDs in offspring.

\section{Evidence of maternal caffeine use during pregnancy and CHD}

Caffeine is a natural component of coffee, tea, cocoa, and cola products. It is teratogenic in animal studies when administered at high concentrations [34]. In humans, caffeine and its metabolites easily cross the placenta and reach the fetus [24]. Most studies on the human teratogenicity of caffeine have not shown an important effect. In a systematic review published on 2006 [23] investigating the association between maternal exposure to caffeine and risk of congenital anomalies, slight elevations were observed for associations between coffee intake and cardiovascular malformations (OR, 1.10; 95\%CI, 0.901.50), but not for the association between tea and cardiovascular malformations (OR, 1.00; 95\%CI, 0.901.20). Fixler and colleagues observed an OR of 0.75 (95\% CI, 0.39-1.44) for the occurrence of cardiac defects with coffee consumed daily and an OR of 0.89 (95\% CI, 0 .421.88) for consumption of caffeine in general [24]. In a case-control study which evaluated risk factors present during early pregnancy in a multiracial population of 687 infants with Down syndrome, the proportion of mothers who drank four or more cups of coffee daily $(4.2 \%)$ was too small to analyze high caffeine intake from either tea or soft drinks [25].

\section{Evidence of maternal body mass index during pregnancy and CHD}

Nowadays, obesity rates have an increasing tendency, since the incidence of obesity in both developed and developing countries is still rising over the years. Epidemiologic data from the National Health and Nutrition Examination Survey described that, from 2007-2008, $28-32 \%$ of childbearing-aged women were obese and that $7.2-8.4 \%$ of them were morbidly obese (BMI $\geq 40 \mathrm{~kg} / \mathrm{m}^{2}$ ) [35]. From a public health perspective, recent studies have highlighted the increased risks that are associated with obesity in pregnancy and have appealed for optimal treatment of the pre gravid obese women. Numerous studies have shown that obese women appear to be at a higher risk of pregnancy complications, such as preeclampsia, gestational diabetes mellitus, preterm delivery, and cesarean delivery [36-39], as well as adverse fetal and neonatal outcomes, such as congenital heart defect. A meta-analysis of 18 studies published between 1966 and 2008 found an association of maternal obesity with an increased risk of cardiovascular anomalies (OR, 1.30; 95\% CI, 1.12-1.51) and septal anomalies (OR, 1.20; 95\% CI, 1.09-1.31) [26]. A recent meta-analysis of 14 epidemiological studies [27] demonstrated an association between overweight, moderate obesity, and severe obesity and all CHD combined (OR, 1.08, 95\% CI, 1.02-1.15; OR, 1.15, 95\% CI, 1.11-1.20; and OR, 1.39, 95\% CI, 1.311.47 , respectively) as well as some individual defects such as pulmonary valve stenosis, hypoplastic left heart syndrome, and outflow tract defects, with the highest risk of tetralogy of Fallot for obese mothers for (OR, 1.94; $95 \% \mathrm{CI}, 1.49-2.51)$. Being underweight did not 
increase the risk of any of the aforementioned CHDs but did increase the risk of aortic valve stenosis (OR, 1.47; 95\% CI, 1.01-2.15). In a more recent case-control study that evaluated the risk of congenital anomalies with different doses of maternal pre-pregnancy obesity in Florida, five CHD phenotypes showed evidence of a dose-response pattern with increasing severity of maternal obesity corresponding to increased odds of each defect [28]. In case-control studies, obesity is a complex condition that should to be studied carefully to minimize underreporting of body weight. We also should take into account the possibility of confounding by other factors associated with nutrition, such as the use of multivitamin supplements or intake of micronutrients.

\section{Evidence of maternal psychological factors and CHD}

Maternal stress is measured by maternal reports of divorce, separation, job loss, or death of a close relative or friend. A large registry-based study reported maternal emotional stress may be a risk factor for CHDs in infants, using bereavement around conception as an indicator of maternal exposure to stress (OR $=1.11,95 \%$ CI $1.00-1.22)$. The association was most for infants of mothers who had lost a partner or child $(\mathrm{OR}=1.32,1.04-1.67)$ [29]. Maternal mental stress during early pregnancy was significant associated with aggregate cardiac defects in a hospital-based case-control study of 164 patients with CHDs (OR, 3.93; 95\% CI, 1.94-7.94) [30]. No increased risk of major cardiac malformations among offspring was seen of women who had high stress level compared with low stress level in a case-control study of 237 cases [16].

\section{Discussion and conclusion}

The reviewed studies indicate that maternal lifestyle factors during pregnancy may contribute to congenital heart defects in the offspring. However, because of differences in methods, these studies are only suggestive. The majority of studies found an association between exposure to tobacco smoking during pregnancy and infant's risk of CHDs, but not all subtypes of CHDs. The results for alcohol exposure were also inconsistent, and some papers included in this review only showed a statistically significant association with specific groups or phenotypes. Only half of the papers showed a statistically significant association between maternal illicit drug use during pregnancy and CHD. Most studies showed that increasing maternal body mass index was associated with an increased risk of CHDs; severe obesity was an even greater risk factor for the development of CHDs. However, the results for studies about maternal caffeine use and psychological factors were mixed.

In interpreting findings on possible associations between maternal lifestyle factors and CHDs, we must remember that such associations from observational studies may be due to the exposures or factors of interest, but they may also be a result of chance, bias, or confounding. An observational study can yield an association as a result of sampling variation of the controls or multiple comparisons in an exploratory study. Since the assessment of exposure to many factors is often based on parental recall after the birth of the child, recall bias should be concerned [7].

The mechanisms by which maternal lifestyle factors may result in CHDs still remain unknown. Findings have shown that maternal smoking has adverse effects on the developing fetus, including hypoxia caused by carbon monoxide, nicotine, and reduction in the supply of essential nutrients to the embryonic tissues [40,41]. Additionally, polycyclic aromatic hydrocarbons, common components of cigarette smoke, are suspected teratogens in laboratory animals and humans [42,43]. The mechanisms by which alcohol consumption may result in CHDs remain to get confirmed, even though its etiology has been the focus of much study, especially the cellular and molecular mechanisms [44-46]. Additionally, findings have shown that alcohol consumption during pregnancy may affect the $\mathrm{Wnt} / \beta$-catenin signaling which allows normal gene activation and cardiogenesis [47]. Cell death is a hypothesized mechanism for muscular VSD formation and alcohol exposure has been shown to result in abnormal cell development and cell death [48]. Cocaine or marijuana, a vasoconstrictor, has been investigated as a potential teratogen because exposure may result in vascular disruptions and hypoperfusion. Some studies among humans have reported intake of caffeine or coffee could induce increased levels of homocysteine and decreases in insulin sensitivity [49]. Vascular disruption, increased homocysteine levels, and oxidative stress associated with hyperglycemia are potential mechanisms for various congenital malformations [50-52]. For the same reason, women who are obese might have diabetes mellitus, which appears to be an important pathogenetic factor that is associated with a wide spectrum of CHDs [53]. Maternal stress could affect fetal development by several plausible mechanisms, such as catecholamine production and corticosteroid production, which may be associated with the development of birth defects. Another potential mechanism is that stress may lead to harmful coping behaviors (e.g., increased substance use or cigarette smoking or decreased dietary quality) and therefore affect development indirectly.

In conclusion, this review summarizes the current state of knowledge of maternal lifestyle factors that may increase the likelihood of congenital heart defects in offspring. To date, no public policies or interventions are specifically directed at reducing the public health impact of congenital heart defects [7]. Our findings could cause public health policy makers to pay more attention to at-risk populations and could be used in the development of population-based prevention strategies to reduce the incidence and burden of 
CHDs, especially women who smoke during pregnancy and have an excessive BMI. However, more prospective studies are needed to further investigate the association between maternal lifestyle factors and CHDs, especially with regard to the different subtypes of CHDs.

\section{Abbreviations}

CHD: Congenital heart defect; BMI: Body mass index; OR: Odds ratio; Cl: Confidence interval; VSD: Ventricular septal defect; ASD: Atrial septal defect; TOF: Tetralogy of fallot; TGA: Transposition of the great arteries; AVSD: Atrioventricular septal defect; CTD: Conotruncal defects; VPS: Valvar pulmonary stenosis; COA: Coarctation of the aorta; AVS: Aortic valve stenosis; PAS: Pulmonary artery stenosis.

\section{Competing interest}

The authors declare that they have no competing interest.

\section{Authors' contributions}

YF, YD and XMM have made substantial contributions to conception and design of the review, interpretation of data, and revising the manuscript critically for important intellectual content; LY, MD and ZQW, have made substantial contributions to conception and design of the review, acquisition of data and analysis, interpretation of data, and drafting the manuscript; $\mathrm{YL}$, BXN, and SW have made substantial contributions to acquisition of data and analysis, and drafting the manuscript. All authors have given final approval of the version to be published.

\section{Authors' information}

Dr. XMM, the vice-president of the Affiliated Children's Hospital of Nanjing Medical University, director of cardiothoracic surgery, doctoral supervisor, chief physicians.

\section{Author details}

'Department of Cardiothoracic Surgery, The Affiliated Children's Hospital of Nanjing Medical University, Nanjing, Jiangsu, P.R. China. ${ }^{2}$ Department of Epidemiology and Biostatistics, Jiangsu Key Lab of Cancer Biomarkers, Prevention and Treatment, Cancer Center, School of Public Health, Nanjing Medical University, Nanjing, Jiangsu, P.R. China.

Received: 22 June 2014 Accepted: 17 October 2014

Published online: 11 November 2014

\section{References}

1. Rosamond W, Flegal K, Friday G, Furie K, Go A, Greenlund K, Haase N, Ho M, Howard V, Kissela B, Kittner S, Lloyd-Jones D, McDermott M, Meigs J, Moy C, Nichol G, O'Donnell CJ, Roger V, Rumsfeld J, Sorlie P, Steinberger J, Thom T, Wasserthiel-Smoller S, Hong Y, American Heart Association Statistics Committee and Stroke Statistics Subcommittee: Heart disease and stroke statistics-2007 update: a report from the American Heart Association Statistics Committee and Stroke Statistics Subcommittee. Circulation 2007, 115:e69-e171.

2. Pierpont ME, Basson CT, Benson DW Jr, Gelb BD, Giglia TM, Goldmuntz E, McGee G, Sable CA, Srivastava D, Webb CL, American Heart Association Congenital Cardiac Defects Committee CoCDitY: Genetic basis for congenital heart defects: current knowledge: a scientific statement from the American Heart Association Congenital Cardiac Defects Committee, Council on Cardiovascular Disease in the Young: endorsed by the American Academy of Pediatrics. Circulation 2007, 115:3015-3038.

3. Gatzoulis MA: Adult congenital heart disease: a cardiovascular area of growth in urgent need of additional resource allocation. Int J Cardiol 2004, 97(Suppl 1):1-2.

4. van der Bom T, Zomer AC, Zwinderman AH, Meijboom FJ, Bouma BJ, Mulder BJ: The changing epidemiology of congenital heart disease. Nat Rev Cardiol 2011, 8:50-60.

5. Kavey RE, Allada V, Daniels SR, Hayman LL, McCrindle BW, Newburger JW, Parekh RS, Steinberger J, American Heart Association Expert Panel on Population and Prevention Science, American Heart Association Council on Cardiovascular Disease in the Young, American Heart Association Council on Epidemiology and Prevention, American Heart Association Council on Nutrition, Physical Activity and Metabolism, American Heart Association
Council on High Blood Pressure Research, American Heart Association Council on Cardiovascular Nursing, American Heart Association Council on the Kidney in Heart Disease, Interdisciplinary Working Group on Quality of Care and Outcomes Research: Cardiovascular risk reduction in high-risk pediatric patients: a scientific statement from the American Heart Association Expert Panel on Population and Prevention Science; the Councils on Cardiovascular Disease in the Young, Epidemiology and Prevention, Nutrition, Physical Activity and Metabolism, High Blood Pressure Research, Cardiovascular Nursing, and the Kidney in Heart Disease; and the Interdisciplinary Working Group on Quality of Care and Outcomes Research: endorsed by the American Academy of Pediatrics. Circulation 2006, 114:2710-2738.

6. Wolf M, Basson CT: The molecular genetics of congenital heart disease: a review of recent developments. Curr Opin Cardiol 2010, 25:192-197.

7. Jenkins KJ, Correa A, Feinstein JA, Botto L, Britt AE, Daniels SR, Elixson M, Warnes CA, Webb CL, American Heart Association Council on Cardiovascular Disease in the $Y$ : Noninherited risk factors and congenital cardiovascular defects: current knowledge: a scientific statement from the American Heart Association Council on Cardiovascular Disease in the Young: endorsed by the American Academy of Pediatrics. Circulation 2007, 115:2995-3014.

8. Kallen K: Maternal smoking and congenital heart defects. Eur J Epidemiol 1999, 15:731-737.

9. Hackshaw A, Rodeck C, Boniface S: Maternal smoking in pregnancy and birth defects: a systematic review based on 173687 malformed cases and 11.7 million controls. Hum Reprod Update 2011, 17:589-604.

10. Lee $L$, Lupo PJ: Maternal smoking during pregnancy and the risk of congenital heart defects in offspring: a systematic review and metaanalysis. Pediatr Cardiol 2013, 34:398-407.

11. Baardman ME, Kerstjens-Frederikse WS, Corpeleijn E, de Walle HE, Hofstra RM, Berger RM, Bakker MK: Combined adverse effects of maternal smoking and high body mass index on heart development in offspring: evidence for interaction? Heart 2012, 98:474-479.

12. Patel SS, Burns TL, Botto LD, Riehle-Colarusso TJ, Lin AE, Shaw GM, Romitti PA National Birth Defects Prevention S: Analysis of selected maternal exposures and non-syndromic atrioventricular septal defects in the National Birth Defects Prevention Study, 1997-2005. Am J Med Genet A 2012, 158A:2447-2455

13. Carmichael SL, Shaw GM, Yang W, Lammer EJ: Maternal periconceptional alcohol consumption and risk for conotruncal heart defects. Birth Defects Res A Clin Mol Teratol 2003, 67:875-878.

14. Grewal J, Carmichael SL, Ma C, Lammer EJ, Shaw GM: Maternal periconceptional smoking and alcohol consumption and risk for select congenital anomalies. Birth Defects Res A Clin Mol Teratol 2008, 82:519-526.

15. Strandberg-Larsen K, Skov-Ettrup LS, Gronbaek M, Andersen AM, Olsen J, Tolstrup J: Maternal alcohol drinking pattern during pregnancy and the risk for an offspring with an isolated congenital heart defect and in particular a ventricular septal defect or an atrial septal defect. Birth Defects Res A Clin Mol Teratol 2011, 91:616-622.

16. Mateja WA, Nelson DB, Kroelinger CD, Ruzek S, Segal J: The association between maternal alcohol use and smoking in early pregnancy and congenital cardiac defects. J Womens Health (Larchmt) 2012, 21:26-34.

17. Liu S, Joseph KS, Lisonkova S, Rouleau J, Van den Hof M, Sauve R, Kramer MS, Canadian Perinatal Surveillance S: Association between maternal chronic conditions and congenital heart defects: a population-based cohort study. Circulation 2013, 128:583-589.

18. O'Leary CM, Elliott EJ, Nassar N, Bower C: Exploring the potential to use data linkage for investigating the relationship between birth defects and prenatal alcohol exposure. Birth Defects Res A Clin Mol Teratol 2013, 97:497-504.

19. Kuciene R, Dulskiene V: Maternal socioeconomic and lifestyle factors during pregnancy and the risk of congenital heart defects. Medicina (Kaunas) 2009, 45:904-909.

20. Williams $\sqcup$, Correa A, Rasmussen S: Maternal lifestyle factors and risk for ventricular septal defects. Birth Defects Res A Clin Mol Teratol 2004, 70:59-64.

21. Ewing CK, Loffredo CA, Beaty TH: Paternal risk factors for isolated membranous ventricular septal defects. Am J Med Genet 1997, 71:42-46.

22. Steinberger $E K$, Ferencz C, Loffredo CA: Infants with single ventricle: a population-based epidemiological study. Teratology 2002, 65:106-115.

23. Browne ML: Maternal exposure to caffeine and risk of congenital anomalies: a systematic review. Epidemiology 2006, 17:324-331. 
24. Fixler DE, Threlkeld N: Prenatal exposures and congenital heart defects in Down syndrome infants. Teratology 1998, 58:6-12.

25. Torfs CP, Christianson RE: Maternal risk factors and major associated defects in infants with Down syndrome. Epidemiology 1999, 10:264-270.

26. Stothard K, Tennant PW, Bell R, Rankin J: Maternal overweight and obesity and the risk of congenital anomalies: a systematic review and meta-analysis. JAMA 2009, 301:636-650.

27. Cai GJ, Sun XX, Zhang L, Hong Q: Association between maternal body mass index and congenital heart defects in offspring: a systematic review. Am J Obstet Gynecol 2014, 211:91-117.

28. Block SR, Watkins SM, Salemi JL, Rutkowski R, Tanner JP, Correia JA, Kirby RS: Maternal pre-pregnancy body mass index and risk of selected birth defects: evidence of a dose-response relationship. Paediatr Perinat Epidemio 2013, 27:521-531.

29. Zhu JL, Olsen J, Sorensen HT, Li J, Nohr EA, Obel C, Vestergaard M, Olsen MS: Prenatal maternal bereavement and congenital heart defects in offspring: a registry-based study. Pediatrics 2013, 131:e1225-e1230.

30. Liu S, Liu J, Tang J, Ji J, Chen J, Liu C: Environmental risk factors for congenital heart disease in the Shandong Peninsula, China: a hospital-based case-control study. J Epidemiol 2009, 19:122-130.

31. Alberman ED, Goldstein H: Possible teratogenic effect of cigarette smoking. Nature 1971, 231:529-530.

32. Chehab G, El-Rassi I, Adhami A, Chokor I, Chatila F, Haddad W, Saliba Z: Parental smoking during early pregnancy and congenital heart defects. J Med Liban 2012, 60:14-18.

33. Clarren SK, Smith DW: The fetal alcohol syndrome. N Engl J Med 1978, 298:1063-1067.

34. Nehlig A, Debry G: Potential teratogenic and neurodevelopmental consequences of coffee and caffeine exposure: a review on human and animal data. Neurotoxicol Teratol 1994, 16:531-543.

35. Flegal KM, Carroll MD, Ogden CL, Curtin LR: Prevalence and trends in obesity among US adults, 1999-2008. JAMA 2010, 303:235-241.

36. Athukorala C, Rumbold AR, Willson KJ, Crowther CA: The risk of adverse pregnancy outcomes in women who are overweight or obese. BMC Pregnancy Childbirth 2010, 10:56.

37. Sebire NJ, Jolly M, Harris JP, Wadsworth J, Joffe M, Beard RW, Regan L, Robinson S: Maternal obesity and pregnancy outcome: a study of 287,213 pregnancies in London. Int J Obes Relat Metab Disord 2001, 25:1175-1182

38. Abenhaim HA, Kinch RA, Morin L, Benjamin A, Usher R: Effect of prepregnancy body mass index categories on obstetrical and neonatal outcomes. Arch Gynecol Obstet 2007, 275:39-43.

39. Weiss JL, Malone FD, Emig D, Ball RH, Nyberg DA, Comstock CH, Saade G, Eddleman K, Carter SM, Craigo SD, Carr SR, D'Alton ME, FASTER Research Consortium: Obesity, obstetric complications and cesarean delivery rate-a population-based screening study. Am J Obstet Gynecol 2004, 190:1091-1097.

40. Alverson CJ, Strickland MJ, Gilboa SM, Correa A: Maternal smoking and congenital heart defects in the Baltimore-Washington Infant Study. Pediatrics 2011, 127:e647-e653.

41. van Rooij IA, Wegerif MJ, Roelofs HM, Peters WH, Kuijpers-Jagtman AM Zielhuis GA, Merkus HM, Steegers-Theunissen RP: Smoking, genetic polymorphisms in biotransformation enzymes, and nonsyndromic oral clefting: a gene-environment interaction. Epidemiology 2001, 12:502-507.

42. Lupo PJ, Langlois PH, Reefhuis J, Lawson CC, Symanski E, Desrosiers TA, Khodr ZG, Agopian AJ, Waters MA, Duwe KN, Finnell RH, Mitchell LE, Moore CA, Romitti PA, Shaw GM, National Birth Defects Prevention Study: Maternal occupational exposure to polycyclic aromatic hydrocarbons: effects on gastroschisis among offspring in the National Birth Defects Prevention Study. Environ Health Perspect 2012, 120:910-915.

43. Barbieri O, Ognio E, Rossi O, Astigiano S, Rossi L: Embryotoxicity of benzo (a)pyrene and some of its synthetic derivatives in Swiss mice. Cancer Res 1986, 46:94-98.

44. Binkhorst M, Wortmann SB, Funke S, Kozicz T, Wevers RA, Morava E: Glycosylation defects underlying fetal alcohol spectrum disorder: a novel pathogenetic model. "When the wine goes in, strange things come out" - S.T. Coleridge, The Piccolomini. J Inherit Metab Dis 2012, 35:399-405.

45. Flentke GR, Garic A, Amberger E, Hernandez M, Smith SM: Calcium-mediated repression of beta-catenin and its transcriptional signaling mediates neural crest cell death in an avian model of fetal alcohol syndrome. Birth Defects Res A Clin Mol Teratol 2011, 91:591-602.
46. Marrs JA, Clendenon SG, Ratcliffe DR, Fielding SM, Liu Q, Bosron WF: Zebrafish fetal alcohol syndrome model: effects of ethanol are rescued by retinoic acid supplement. Alcohol 2010, 44:707-715.

47. Serrano $M$, Han M, Brinez $P$, Linask KK: Fetal alcohol syndrome: cardiac birth defects in mice and prevention with folate. Am J Obstet Gynecol 2010, 203:75 e77-75 e15.

48. Menegola E, Broccia ML, Di Renzo F, Giavini E: Acetaldehyde in vitro exposure and apoptosis: a possible mechanism of teratogenesis. Alcohol 2001, 23:35-39.

49. Ranheim T, Halvorsen B: Coffee consumption and human health-beneficial or detrimental?-Mechanisms for effects of coffee consumption on different risk factors for cardiovascular disease and type 2 diabetes mellitus. Mol Nutr Food Res 2005, 49:274-284.

50. Hobbs CA, Cleves MA, Melnyk S, Zhao W, James SJ: Congenital heart defects and abnormal maternal biomarkers of methionine and homocysteine metabolism. Am J Clin Nutr 2005, 81:147-153.

51. Van Allen Ml: Fetal vascular disruptions: mechanisms and some resulting birth defects. Pediatr Ann 1981, 10:219-233.

52. Loeken MR: Free radicals and birth defects. J Matern Fetal Neonatal Med 2004, 15:6-14

53. Nielsen GL, Norgard B, Puho E, Rothman KJ, Sorensen HT, Czeizel AE: Risk of specific congenital abnormalities in offspring of women with diabetes. Diabet Med 2005, 22:693-696.

doi:10.1186/s13052-014-0085-3

Cite this article as: Feng et al:: Maternal lifestyle factors in pregnancy and congenital heart defects in offspring: review of the current evidence. Italian Journal of Pediatrics 2014 40:85.

\section{Submit your next manuscript to BioMed Central and take full advantage of:}

- Convenient online submission

- Thorough peer review

- No space constraints or color figure charges

- Immediate publication on acceptance

- Inclusion in PubMed, CAS, Scopus and Google Scholar

- Research which is freely available for redistribution 